\title{
Article \\ Horseradish Peroxidase Labelled-Sandwich Electrochemical Sensor Based on Ionic Liquid-Gold Nanoparticles for Lactobacillus brevis
}

\author{
Le Zhao
}

Citation: Zhao, L. Horseradish Peroxidase Labelled-Sandwich Electrochemical Sensor Based on Ionic Liquid-Gold Nanoparticles for Lactobacillus brevis. Micromachines 2021, 12, 75. https://doi.org/ 10.3390/mi12010075

Received: 26 November 2020 Accepted: 6 January 2021 Published: 12 January 2021

Publisher's Note: MDPI stays neutral with regard to jurisdictional clai$\mathrm{ms}$ in published maps and institutional affiliations.

Copyright: () 2021 by the author. Licensee MDPI, Basel, Switzerland. This article is an open access article distributed under the terms and conditions of the Creative Commons Attribution (CC BY) license (https:// creativecommons.org/licenses/by/ $4.0 /)$.
Key Laboratory of Dairy Science, Ministry of Education, Northeast Agricultural University, Harbin 150030, China; zhaole@neau.edu.cn

\begin{abstract}
Lactobacillus brevis is the most common bacteria that causes beer spoilage. In this work, a novel electrochemical immunosensor was fabricated for ultra-sensitive determination of L. brevis. Gold nanoparticles (AuNPs) were firstly electro-deposited on the electrode surface for enhancing the electro-conductivity and specific surface area. Ionic liquid was used for improving the immobilization performance of the immunosensor. After optimization, a linear regression equation can be observed between the $\Delta_{\text {current }}$ and concentration of L. brevis from $10^{4} \mathrm{CFU} / \mathrm{mL}$ to $10^{9} \mathrm{CFU} / \mathrm{mL}$. The limit of detection can be estimated to be $10^{3} \mathrm{CFU} / \mathrm{mL}$.
\end{abstract}

Keywords: immunosensor; electrodeposition; Lactobacillus brevis; ionic liquid; beer; cyclic voltammetry

\section{Introduction}

Beer is one of the most popular drinks in the world. The specific physical and chemical properties of beer, such as low temperature anaerobic environment, low $\mathrm{pH}(4.2-4.4)$ and hop bitter substances, can resist the proliferation of general microorganisms. In spite of this, there are still some acid resistant, hop resistant and anaerobic microorganisms in the brewery environment [1-3]. They make use of the intermediate metabolites and autolysates of yeast and bring harm to beer production. Among them, the most destructive to beer are some gram-positive bacteria such as Lactobacillus and Pediococcus. Lactobacillus brevis is the most common bacteria isolated from spoilage beer, which causes more than half of beer spoilage problems. It is also one of the beer spoilage bacteria which has been studied deeply [4-6].

Culture method and biochemical microtubule fermentation method are the most commonly used. Their advantages are convenience and low cost. Their disadvantages are that they take a long time, generally about a week, the precision is not high and the microbial pollution in the production process cannot be controlled in time [7-11]. Adenosine triphosphate (ATP) bioluminescence rapid detection has been applied in public health detection of food industry and pharmaceutical industry. The fluorescence intensity of the reaction is directly proportional to the amount of ATP, so the amount of ATP or microorganism on the membrane can be quantitatively detected according to the standard curve [12-20]. Since this method is based on intracellular ATP, it is only suitable for microbial detection in relatively clean sake and finished beer. Enzyme linked immunosorbent assay or enzymelinked immunosorbent assay (ELISA) can be used to detect low levels of antigen. However, ELISA is actually an optical measurement, and it has some disadvantages in use. These disadvantages require a large, power intensive light source, detector and monochromator. Moreover, the color of the sample will produce potential false signals.

Electrochemical immunosensor is a molecular recognition element based on antigenantibody reaction [21-23]. The concentration signal of a certain chemical substance is transformed into corresponding electrical signal through the sensor element. Electrochemical immunosensor has many advantages, such as good selectivity, variety, low cost and 
online application. It can be widely used in medical treatment, food analysis, industrial production and environmental detection [24-26]. This communication demonstrates the electrochemical assay developed for the detection of L. brevis. The immunosensor fabrication has involved using gold nanoparticles (AuNPs) to enhance the immobilization ability. AuNPs have been widely used for immunosensor fabrication due to their excellent conductivity for enhancing the signal [27]. In addition, ionic liquid and chitosan have been used for further enhancing the stability of antibody due to the binding and blanketing effect [28,29]. Especially, the bioactivity of biospecies could be maintained and their electrochemical activity could be promoted in ionic liquid. The proposed electrochemical immunosensor showed excellent sensing performance towards the L. brevis detection.

\section{Materials and Methods}

\subsection{Reagents and Instrument}

Escherichia coli (E. coli, CICC 10003), Staphylococcus aureus (S. aureus, CICC 21600), Bacillus subtilis (B. subtilis, CICC 10028) and L. brevis (CICC 20014) were purchased from China Center of Industrial Culture Collection, Beijing, China. Anti-L. brevis and horseradish peroxidase (HRP)-labeled anti-L. brevis were purchased from ChinaPeptides Co. Ltd., Shanghai, China. $\mathrm{HAuCl}_{4}$, 1-Butyl-3-methylimidazolium hexafluorophosphate (ILs), chitosan and thionine were purchased from 9dingchem Co. Ltd., Shanghai, China. All other chemicals were analytical grade and used without further purification.

All electrochemical experiments were conducted at a CHI760E electrochemical working station. A typical three-electrodes system was used, including a glassy carbon electrode (GCE), a Pt wire and an $\mathrm{Ag} / \mathrm{AgCl}(3 \mathrm{M} \mathrm{KCl})$ electrode.

\subsection{Preparation of Microbial Sample}

All microbes were grown at $37^{\circ} \mathrm{C}$ in nutrient broth. Cells were harvested in late exponential growth phase by centrifugation $(4025 \times \mathrm{g}$ for $20 \mathrm{~min})$ and washed using phosphate buffer saline (PBS). After removal of the supernatant fluid, the pellets were resuspended in $10 \mathrm{~mL}$ PBS. The density of the L. brevis suspension was determined to be $10^{10} \mathrm{CFU} / \mathrm{mL}$. The L. brevis was inactivated $12 \mathrm{~h}$ at room temperature by $0.4 \%$ formaldehyde and stored at $4{ }^{\circ} \mathrm{C}$ until used. The suspension was diluted in $0.9 \% \mathrm{NaCl}$ solution to produce the desired final concentration of $L$. brevis for experiments.

\subsection{Preparation of Electrochemical Immunosensor}

A GCE was firstly polished using $\mathrm{Al}_{2} \mathrm{O}_{3}$ slurry and washed by water and ethanol. Then, AuNPs were electro-deposited on the GCE by reduction of $\mathrm{HAuCl}_{4}$. Typically, GCE was inserted into $20 \mathrm{~mL}$ of $10 \mathrm{mg} / \mathrm{L} \mathrm{HAuCl}_{4}$ solution (containing $1 \% \mathrm{HCl}$ ). Then, a cyclic voltammetry scan between -1 to $1 \mathrm{~V}$ at a scan rate of $10 \mathrm{mV} / \mathrm{s}$ was conducted for two cycles. After electro-deposition, the GCE was rinsed by water and ethanol and dried at room temperature. The AuNPs deposited electrode was denoted as Au/GCE. Two micrograms per litre of anti-L. brevis (1:200 diluted in $0.1 \mathrm{M} \mathrm{PBS,} \mathrm{pH} 7.4)$ were coated on the above electrode and stored at $4{ }^{\circ} \mathrm{C}$ for $12 \mathrm{~h}$. Five micrograms per litre of $1 \%(v / v)$ ILs or $1 \%$ chitosan (CS) was dip coated on the above electrode surface and dried at room temperature. The electrode was washed gently with PBS to remove excess antibody. Then, the electrode was immersed into a bovine serum albumin (BSA) solution $(w / w, 0.25 \%)$ for blocking all active sites. The modified immunosensors were denoted as ILs/anti-L. brevis/Au/GCE or CS/anti-L. brevis/Au/GCE. The scheme of preparation of the immunosensor is shown in Figure 1. 


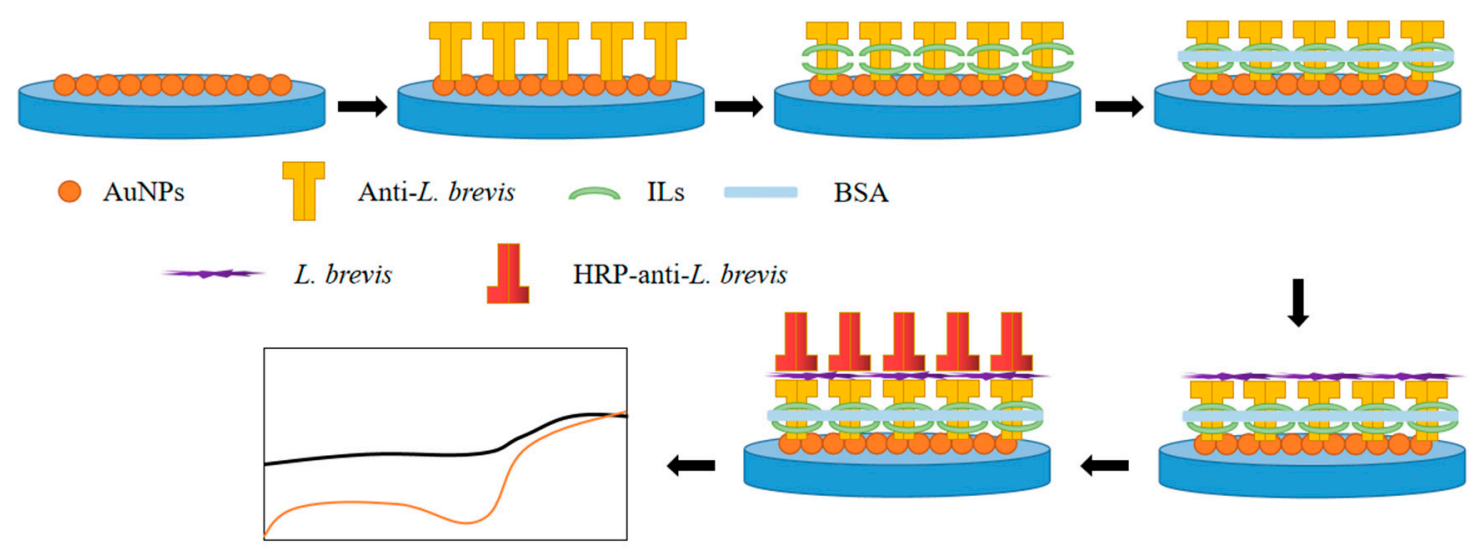

Figure 1. Scheme of preparation of Lactobacillus brevis immunosensor.

\subsection{Electrochemical Detection of L. brevis}

Five micrograms per litre of L. brevis was dropped onto the ILs/anti-L. brevis/Au/GCE and incubated at $35^{\circ} \mathrm{C}$ for half an hour and rinsed by PBS. The electrode was denoted as L. brevis/ILs/anti-L. brevis/Au/GCE. Then, $5 \mu \mathrm{L}$ of HRP-anti-L. brevis was coated on the above electrode and then inserted into a $0.1 \mathrm{M}$ ABS (pH 6.5) with $1 \mathrm{mM}$ thionine and $0.5 \mathrm{mM} \mathrm{H}_{2} \mathrm{O}_{2}$. CV has been used for sensing analysis. The reduction peak before and after the immune reaction has been used as an indicator. All electrochemical measurements were repeated at least five times to ensure the reproducibility.

\section{Results and Discussion}

Electrochemical deposition of AuNPs can improve the performance of the immunosensor and enhance the immobilization ability of the electrode surface. Figure 2A shows the surface of GCE deposited with AuNPs. It can be seen from the figure that there are about $30 \mathrm{~nm}$ AuNPs on the surface of the electrode. The size of the nanoparticles is uniform, which ensures the repeatability of the immunosensor [30]. Figure 2B shows the surface of the L. brevis/ILs/anti-L. brevis/Au/GCE. The immobilization of antibody showed the coverage of the AuNPs, while the L. brevis was absorbed on the electrode surface.
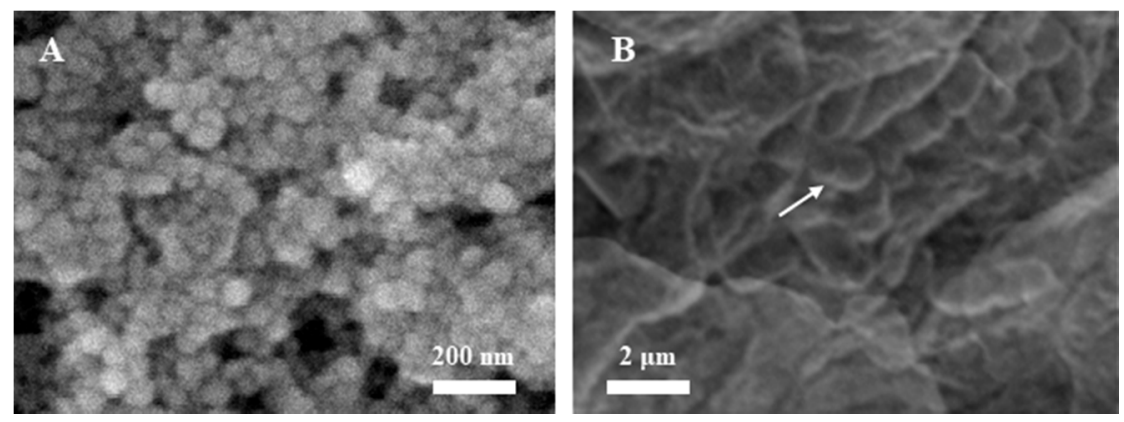

Figure 2. SEM image of (A) electro-deposited gold nanoparticles (AuNPs) and (B) L. brevis/ILs/antiL. brevis/Au/GCE.

ILs and CS are two substances that are often used to improve the stability of immunosensors. This study compared the effects of the two substances. Figure 3 shows the CV of L. brevis/ILs/anti-L. brevis/Au/GCE and L. brevis/CS/anti-L. brevis/Au/GCE before and after immune response. It can be seen from the figure that L. brevis/ILs/anti-L. brevis/Au/GCE can reduce more $\mathrm{H}_{2} \mathrm{O}_{2}$ after immune reaction, indicating that more HRPanti-L. brevis is loaded on the electrode surface. The results show that ILs can provide an excellent microenvironment for microorganisms [31-33], and that the loaded substances can maintain high bioactivity. Therefore, ILs was selected as the stabilizer of immune sensor in the follow-up work. 


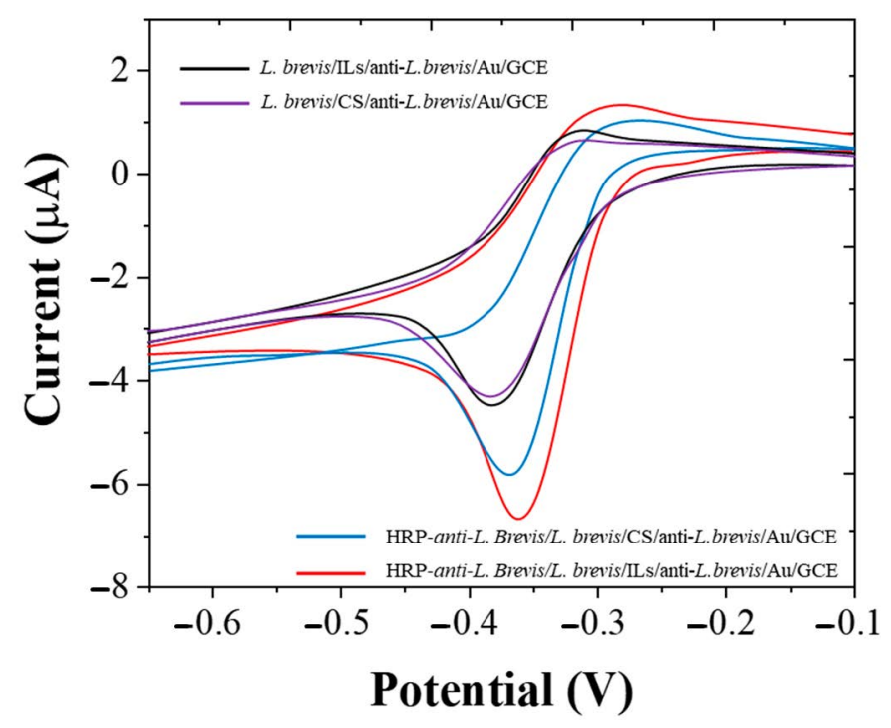

Figure 3. CVs of L. brevis/ILs/anti-L. brevis/Au/GCE, L. brevis/CS/anti-L. brevis/Au/GCE, HRPanti-L. brevis/L. brevis/ILs/anti-L. brevis/Au/GCE and HRP-anti-L. brevis/L. brevis/CS/anti-L. brevis/Au/GCE.

Figure 4 shows the EIS behavior changes during the fabrication of immunosensors. Five $\mathrm{mM}\left[\mathrm{Fe}\left(\mathrm{CN}_{6}\right)\right]^{3-/ 4-}$ was used as a probe. It can be seen from Figure 4 , bare GCE showed the highest $R_{c t}$ compared with other electrodes, suggesting the electro-deposition could significantly enhance the electron transfer rate. Then, a clear increase of the $R_{c t}$ was noted after the immobilization of anti-L. brevis. It indicates the successful modification. A further increasing of the $R_{c t}$ has been observed with the immobilization of BSA, $L$. brevis, HRP-anti-L. brevis and L. brevis, suggesting the successful modification of each step. The increase of $R_{c t}$ during the sensor fabrication is due to the formation of barriers during the antibody-antigen reaction [34,35]. On the other hand, the coating of ILs only affects the $\mathrm{R}_{\mathrm{ct}}$ slightly, suggesting the ILs is an ideal candidate for enhancing the loading performance of the electrode.

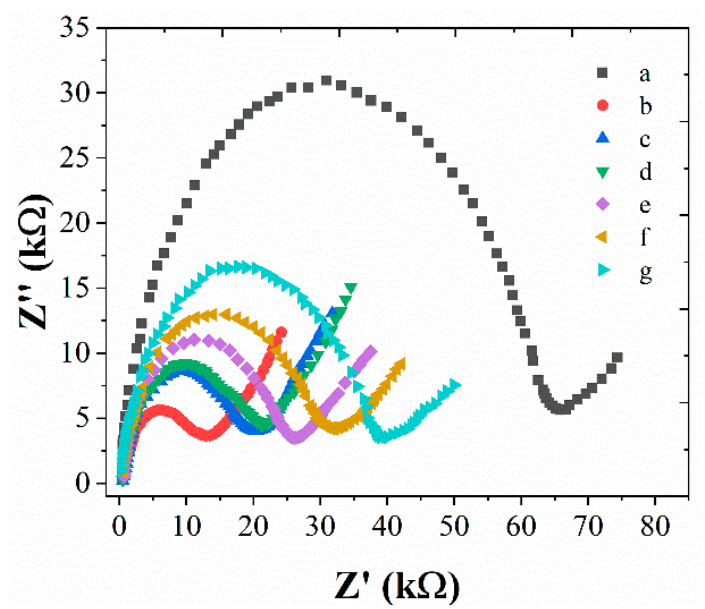

Figure 4. EISs of (a) bare glassy carbon electrode (GCE); (b) Au/GCE; (c) anti-L. brevis/Au/GCE; (d) ILs/anti-L. brevis/Au/GCE; (e) BSA/ILs/anti-L. brevis/Au/GCE; (f) L. brevis/BSA/ILs/antiL. brevis/Au/GCE; (g) HRP-anti-L. brevis/L. brevis/BSA/ILs/anti-L. brevis/Au/GCE in $5 \mathrm{mM}$ $\left[\mathrm{Fe}\left(\mathrm{CN}_{6}\right)\right]^{3-/ 4-}$.

The effect of CV scan rate on the immunosensor can be used to investigate the electron transfer type on the electrode surface. Figure 5A shows the effect of the scan rate of the from 10 to $100 \mathrm{mV} / \mathrm{s}$. It can be seen that the anodic and cathodic peak currents increased 
linearly with the square root of scan rates. This behavior indicates the immunosensor had a diffusion controlled redox process $[16,17,36]$.

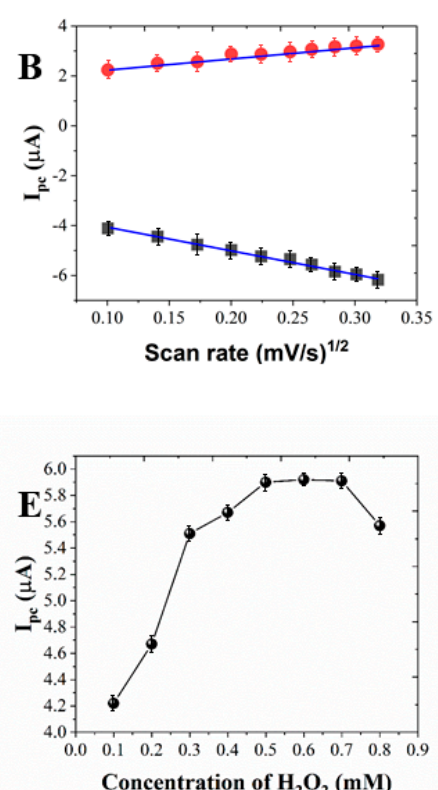
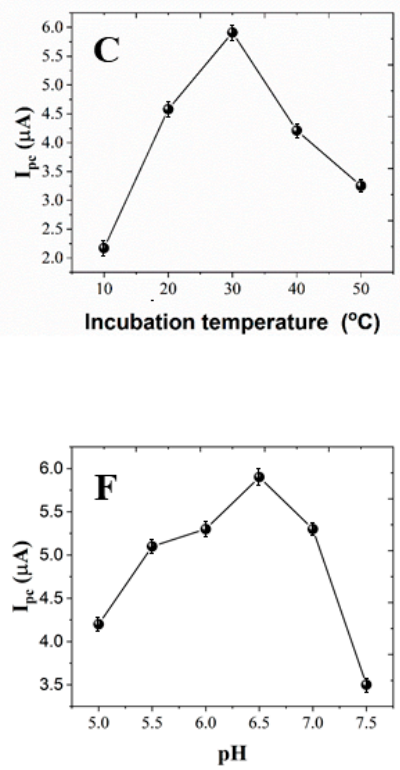

Figure 5. (A) Effect of incubation time between L. brevis and HRP-anti-L. brevis on the immunosensor. (B) Current response vs. square root of scan rate (red points and blue points for oxidation and reduction, respectively). (C) Effect of incubation temperature on the immunosensor. (D) Effect of incubation time between anti-L. brevis and L. brevis on the immunosensor.

(E) Effect of concentration of $\mathrm{H}_{2} \mathrm{O}_{2}$ on the immunosensor. (F) Effect of $\mathrm{pH}$ condition on the immunosensor.

The acidic or alkaline condition can influence the activity of the antibody [9,10,37-39]. Figure $5 \mathrm{~B}$ shows the effect of $\mathrm{pH}$ on the immunosensor. It can be seen that the peak current increased along with the $\mathrm{pH}$ from 5 to 6.5 , and reached the maximum at 6.5. Further increase of $\mathrm{pH}$ showed decrease of the current. Therefore, $\mathrm{pH} 6.5$ has been used for sensing.

Figure $5 \mathrm{C}$ shows the effect of the $\mathrm{H}_{2} \mathrm{O}_{2}$ concentration on the immunosensor. The increase of the $\mathrm{H}_{2} \mathrm{O}_{2}$ concentration can significantly enhance the sensing performance on the beginning stage due to more $\mathrm{H}_{2} \mathrm{O}_{2}$ participating in the enzymatic reaction [40-42]. The current change reached a plateau after $0.5 \mathrm{mM}$. A decreasing of the current was observed when the concentration exceeded $0.7 \mathrm{mM}$.

Figure 5D shows the effect of incubation temperature on the immunosensor. It can be seen that the maximum current was observed at $30^{\circ} \mathrm{C}$. Therefore, $30^{\circ} \mathrm{C}$ incubation has been used for study. Figure 5E shows the effect of the incubation time between anti-L. brevis and $L$. brevis on the immunosensor. The increase of the incubation time can significantly enhance the sensing performance on the beginning stage. The current change reached a plateau after $40 \mathrm{~min}$. Therefore, $40 \mathrm{~min}$ incubation has been used for study. Figure 5F shows the effect of the incubation time between L. brevis and HRP-anti-L. brevis on the immunosensor. Similarly, the increase of the incubation time can significantly enhance the sensing performance on the beginning stage. The current change reached a plateau after $30 \mathrm{~min}$. Therefore, $30 \mathrm{~min}$ incubation has been used for study.

The sensing performance of the immunosensor was investigated under the optimum conditions. Figure $6 \mathrm{~A}$ shows the $\mathrm{CVs}$ of the immunosensor towards different concentrates of L. brevis. As shown in Figure 6B, the $\Delta_{\text {current }}$ increased along with the the concentrate of L. brevis from $10^{1}$ to $10^{10} \mathrm{CFU} / \mathrm{mL}$. The increase of the $\Delta_{\text {current }}$ is due to more L. brevis being absorbed on the electrode surface, which consequently increased the HRP-anti- $L$. brevis absorption. Then, the HRP-anti-L. brevis could catalyze the $\mathrm{H}_{2} \mathrm{O}_{2}$ reduction and contribute to the signal. A linear regression equation can be observed between the $\Delta_{\text {current }}$ and concentration of L. brevis from $10^{4} \mathrm{CFU} / \mathrm{mL}$ to $10^{9} \mathrm{CFU} / \mathrm{mL}$. The limit of detection can be estimated to be $10^{3} \mathrm{CFU} / \mathrm{mL}$. Table 1 shows the comparison of proposed immunosensor 
with previous published works. It can been seen that the immunosensor fabricated in this work showed competitive performance. To further improve the detection sensitivity of the immunosensor, additional probes such as enzyme-assisted catalytic reaction can be included along with the L. brevis immobilization in the future work.
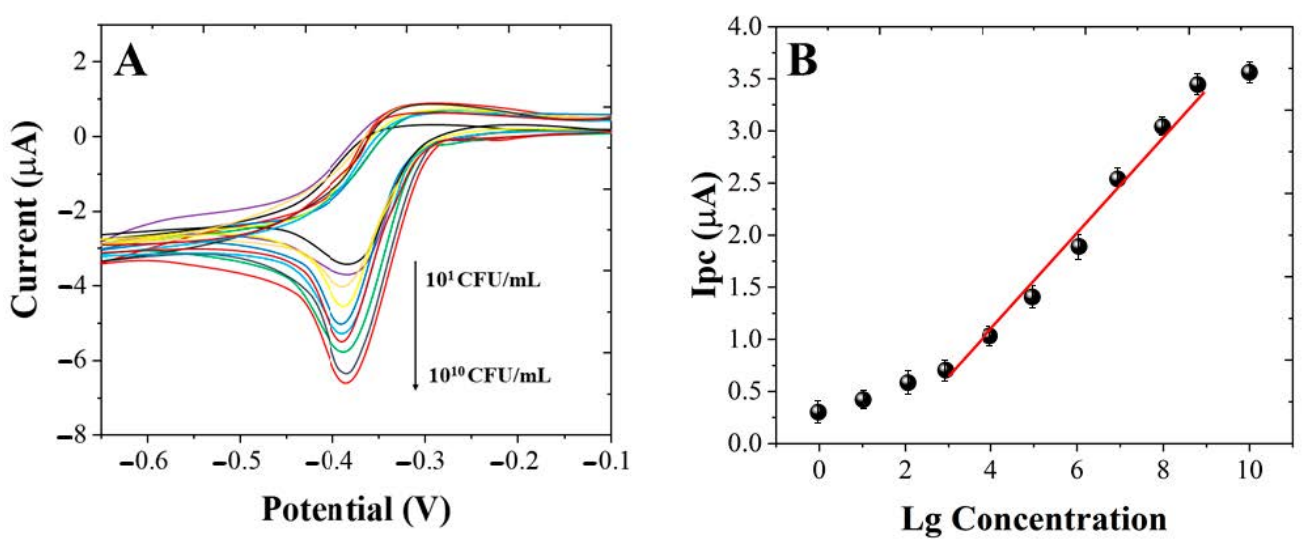

Figure 6. (A) CVs of immunosensor towards $10^{1}, 10^{2}, 10^{3}, 10^{4}, 10^{5}, 10^{6}, 10^{7}, 10^{8}, 10^{9}$ and $10^{10} \mathrm{CFU} / \mathrm{mL}$ of L. brevis (an arrow indicates the direction of the increasing L. brevis concentration, from $10^{1}$ to $10^{10} \mathrm{CFU} / \mathrm{mL}$ ). (B) Plots and linear fitting line of $\Delta_{\text {current }}$ against the concentrates of L. brevis.

Table 1. Comparison of sensing performance towards L. brevis.

\begin{tabular}{cccc}
\hline Sensing Method & Detection Linear Range & Limit of Detection & Reference \\
\hline $\begin{array}{c}\text { Electrochemical sandwich assay } \\
\text { Propidium monoazide } \\
\text { pretreatment-PCR }\end{array}$ & 400 to $800 \mathrm{CFU} / \mathrm{mL}$ & $40 \mathrm{CFU} / \mathrm{mL}$ & {$[43]$} \\
$\begin{array}{c}\text { Electrochemical immunosensor } \\
\text { E }\end{array}$ & $10^{4}$ to $10^{9} \mathrm{CFU} / \mathrm{mL}$ & $10^{4} \mathrm{CFU} / \mathrm{mL}$ & {$[4]$} \\
\hline
\end{tabular}

The specificity of the immunosensor has been tested using $10^{9} \mathrm{CFU} / \mathrm{mL}$ of E. coli, S. aureus and B. subtilis. As shown in Figure 7, the current of immunosensor towards $L$. brevis is significantly larger than that of the sensor towards E. coli, S. aureus and B. subtilis, suggesting the proposed immunosensor had excellent sensing performance. In order to test the use of the proposed immunosensor in beer samples, commercial beer has been tested by replacing the immobilization of L. brevis. No $\Delta_{\text {current }}$ was observed during or after the sensing indicating no detectable L. brevis is found in commercial products. Then, standard addition method was applied during the immobilization process. Five individual immunosensors were fabricated using beer mixed with $10^{5}$ L. brevis during the immobilization process. An RSD of $7.21 \%$ was detected among the five measurements, suggesting the proposed immunosensor can be applied for sensing L. brevis in real beer samples.

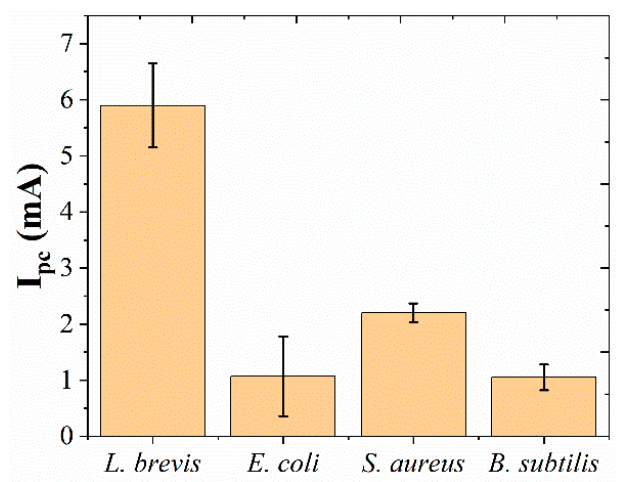

Figure 7. The specificity of immunosensor for L. brevis, E. coli, S. aureus and B. subtilis. 


\section{Conclusions}

In this work, an ultra-sensitive electrochemical immunosensor was fabricated for L. brevis detection. AuNPs were electro-deposited on the electrode surface to enhance the electrochemical performance of the immunosensor. Then, ILs was coated on the immunosensor for enhancing the immobilization performance. Due to the sandwich construction, the proposed electrochemical immunosensor can linear detect $L$. brevis from $10^{4} \mathrm{CFU} / \mathrm{mL}$ to $10^{9} \mathrm{CFU} / \mathrm{mL}$. The limit of detection can be estimated to be $10^{3} \mathrm{CFU} / \mathrm{mL}$.

Funding: This research received no external funding.

Data Availability Statement: The data presented in this study are available on request from the corresponding author.

Conflicts of Interest: The author declares no conflict of interest.

\section{References}

1. Liu, J.; Deng, Y.; Soteyome, T.; Li, Y.; Su, J.; Li, L.; Li, B.; Shirtliff, M.E.; Xu, Z.; Peters, B.M. Induction and Recovery of the Viable but Nonculturable State of Hop-Resistance Lactobacillus Brevis. Front. Microbiol. 2018, 9, 2076. [CrossRef] [PubMed]

2. Bergsveinson, J.; Friesen, V.; Ziola, B. Transcriptome Analysis of Beer-Spoiling Lactobacillus Brevis BSO 464 during Growth in Degassed and Gassed Beer. Int. J. Food Microbiol. 2016, 235, 28-35. [CrossRef] [PubMed]

3. Feyereisen, M.; Mahony, J.; Lugli, G.A.; Ventura, M.; Neve, H.; Franz, C.M.; Noben, J.-P.; O'Sullivan, T.; van Sinderen, D. Isolation and Characterization of Lactobacillus Brevis Phages. Viruses 2019, 11, 393. [CrossRef] [PubMed]

4. Ma, Y.; Deng, Y.; Xu, Z.; Liu, J.; Dong, J.; Yin, H.; Yu, J.; Chang, Z.; Wang, D. Development of a Propidium Monoazide-Polymerase Chain Reaction Assay for Detection of Viable Lactobacillus Brevis in Beer. Braz. J. Microbiol. 2017, 48, 740-746. [CrossRef]

5. Feyereisen, M.; Mahony, J.; O'Sullivan, T.; Boer, V.; van Sinderen, D. Beer Spoilage and Low PH Tolerance Is Linked to Manganese Homeostasis in Selected Lactobacillus Brevis Strains. J. Appl. Microbiol. 2020, 129, 1309-1320. [CrossRef]

6. Riedl, R.; Dünzer, N.; Michel, M.; Jacob, F.; Hutzler, M. Beer Enemy Number One: Genetic Diversity, Physiology and Biofilm Formation of Lactobacillus Brevis. J. Inst. Brew. 2019, 125, 250-260. [CrossRef]

7. Coulup, S.K.; Georg, G.I. Revisiting Microtubule Targeting Agents: $\alpha$-Tubulin and the Pironetin Binding Site as Unexplored Targets for Cancer Therapeutics. Bioorganic Med. Chem. Lett. 2019, 29, 1865-1873. [CrossRef]

8. Chen, G.-Y.; Cleary, J.M.; Asenjo, A.B.; Chen, Y.; Mascaro, J.A.; Arginteanu, D.F.; Sosa, H.; Hancock, W.O. Kinesin-5 Promotes Microtubule Nucleation and Assembly by Stabilizing a Lattice-Competent Conformation of Tubulin. Curr. Biol. 2019, 29, 2259-2269. [CrossRef]

9. Shamsadin-Azad, Z.; Taher, M.A.; Cheraghi, S.; Karimi-Maleh, H. A Nanostructure Voltammetric Platform Amplified with Ionic Liquid for Determination of Tert-Butylhydroxyanisole in the Presence Kojic Acid. J. Food Meas. Charact. 2019, 13, $1781-1787$. [CrossRef]

10. Karimi-Maleh, H.; Karimi, F.; Malekmohammadi, S.; Zakariae, N.; Esmaeili, R.; Rostamnia, S.; Yola, M.L.; Atar, N.; Movaghgharnezhad, S.; Rajendran, S.; et al. An Amplified Voltammetric Sensor Based on Platinum Nanoparticle/Polyoxometalate/ Two-Dimensional Hexagonal Boron Nitride Nanosheets Composite and Ionic Liquid for Determination of N-Hydroxysuccinimide in Water Samples. J. Mol. Liq. 2020, 310, 113185. [CrossRef]

11. Karimi-Maleh, H.; Kumar, B.G.; Rajendran, S.; Qin, J.; Vadivel, S.; Durgalakshmi, D.; Gracia, F.; Soto-Moscoso, M.; Orooji, Y.; Karimi, F. Tuning of Metal Oxides Photocatalytic Performance Using Ag Nanoparticles Integration. J. Mol. Liq. 2020, 314, 113588. [CrossRef]

12. Ngamsom, B.; Wandera, E.A.; Iles, A.; Kimani, R.; Muregi, F.; Gitaka, J.; Pamme, N. Rapid Detection of Group B Streptococcus (GBS) from Artificial Urine Samples Based on IFAST and ATP Bioluminescence Assay: From Development to Practical Challenges during Protocol Testing in Kenya. Analyst 2019, 144, 6889-6897. [CrossRef] [PubMed]

13. Kim, S.U.; Jo, E.-J.; Noh, Y.; Mun, H.; Ahn, Y.-D.; Kim, M.-G. Adenosine Triphosphate Bioluminescence-Based Bacteria Detection Using Targeted Photothermal Lysis by Gold Nanorods. Anal. Chem. 2018, 90, 10171-10178. [CrossRef] [PubMed]

14. Matsui, A.; Niimi, H.; Uchiho, Y.; Kawabe, S.; Noda, H.; Kitajima, I. A Rapid ATP Bioluminescence-Based Test for Detecting Levofloxacin Resistance Starting from Positive Blood Culture Bottles. Sci. Rep. 2019, 9, 1-9. [CrossRef] [PubMed]

15. Fu, L.; Liu, Z.; Ge, J.; Guo, M.; Zhang, H.; Chen, F.; Su, W.; Yu, A. (001) Plan Manipulation of $\alpha$-Fe2O3 Nanostructures for Enhanced Electrochemical Cr(VI) Sensing. J. Electroanal. Chem. 2019, 841, 142-147. [CrossRef]

16. Fu, L.; Zheng, Y.; Zhang, P.; Zhang, H.; Wu, M.; Zhang, H.; Wang, A.; Su, W.; Chen, F.; Yu, J.; et al. An Electrochemical Method for Plant Species Determination and Classification Based on Fingerprinting Petal Tissue. Bioelectrochemistry 2019, 129, 199-205. [CrossRef]

17. Zhou, J.; Zheng, Y.; Zhang, J.; Karimi-Maleh, H.; Xu, Y.; Zhou, Q.; Fu, L.; Wu, W. Characterization of the Electrochemical Profiles of Lycoris Seeds for Species Identification and Infrageneric Relationships. Anal. Lett. 2020, 53, 2517-2528. [CrossRef] 
18. Karimi-Maleh, H.; Karimi, F.; Orooji, Y.; Mansouri, G.; Razmjou, A.; Aygun, A.; Sen, F. A New Nickel-Based Co-Crystal Complex Electrocatalyst Amplified by NiO Dope Pt Nanostructure Hybrid; a Highly Sensitive Approach for Determination of Cysteamine in the Presence of Serotonin. Sci. Rep. 2020, 10, 11699. [CrossRef]

19. Karimi-Maleh, H.; Karimi, F.; Alizadeh, M.; Sanati, A.L. Electrochemical Sensors, a Bright Future in the Fabrication of Portable Kits in Analytical Systems. Chem. Rec. 2020, 20, 682-692. [CrossRef]

20. Karimi-Maleh, H.; Arotiba, O.A. Simultaneous Determination of Cholesterol, Ascorbic Acid and Uric Acid as Three Essential Biological Compounds at a Carbon Paste Electrode Modified with Copper Oxide Decorated Reduced Graphene Oxide Nanocomposite and Ionic Liquid. J. Colloid Interface Sci. 2020, 560, 208-212. [CrossRef]

21. Chen, Y.; Yuan, P.-X.; Wang, A.-J.; Luo, X.; Xue, Y.; Zhang, L.; Feng, J.-J. A Novel Electrochemical Immunosensor for Highly Sensitive Detection of Prostate-Specific Antigen Using 3D Open-Structured PtCu Nanoframes for Signal Amplification. Biosens. Bioelectron. 2019, 126, 187-192. [CrossRef] [PubMed]

22. Hou, Y.-H.; Wang, J.-J.; Jiang, Y.-Z.; Lv, C.; Xia, L.; Hong, S.-L.; Lin, M.; Lin, Y.; Zhang, Z.-L.; Pang, D.-W. A Colorimetric and Electrochemical Immunosensor for Point-of-Care Detection of Enterovirus 71. Biosens. Bioelectron. 2018, 99, 186-192. [CrossRef] [PubMed]

23. Yang, G.; Lai, Y.; Xiao, Z.; Tang, C.; Deng, Y. Ultrasensitive Electrochemical Immunosensor of Carcinoembryonic Antigen Based on Gold-Label Silver-Stain Signal Amplification. Chin. Chem. Lett. 2018, 29, 1857-1860. [CrossRef]

24. Dai, L.; Li, Y.; Wang, Y.; Luo, X.; Wei, D.; Feng, R.; Yan, T.; Ren, X.; Du, B.; Wei, Q. A Prostate-Specific Antigen Electrochemical Immunosensor Based on Pd NPs Functionalized Electroactive Co-MOF Signal Amplification Strategy. Biosens. Bioelectron. 2019, 132, 97-104. [PubMed]

25. Pakchin, P.S.; Ghanbari, H.; Saber, R.; Omidi, Y. Electrochemical Immunosensor Based on Chitosan-Gold Nanoparticle/Carbon Nanotube as a Platform and Lactate Oxidase as a Label for Detection of CA125 Oncomarker. Biosens. Bioelectron. 2018, 122, 68-74. [CrossRef] [PubMed]

26. Wang, Y.; Wang, Y.; Wu, D.; Ma, H.; Zhang, Y.; Fan, D.; Pang, X.; Du, B.; Wei, Q. Label-Free Electrochemical Immunosensor Based on Flower-like Ag/MoS2/RGO Nanocomposites for Ultrasensitive Detection of Carcinoembryonic Antigen. Sens. Actuators B Chem. 2018, 255, 125-132. [CrossRef]

27. Ricci, F.; Adornetto, G.; Palleschi, G. A Review of Experimental Aspects of Electrochemical Immunosensors. Electrochim. Acta 2012, 84, 74-83.

28. Liu, N.; Chen, X.; Ma, Z. Ionic Liquid Functionalized Graphene/Au Nanocomposites and Its Application for Electrochemical Immunosensor. Biosens. Bioelectron. 2013, 48, 33-38. [CrossRef]

29. Suresh, L.; Brahman, P.K.; Reddy, K.R.; Bondili, J. Development of an Electrochemical Immunosensor Based on Gold Nanoparticles Incorporated Chitosan Biopolymer Nanocomposite Film for the Detection of Prostate Cancer Using PSA as Biomarker. Enzym. Microb. Technol. 2018, 112, 43-51.

30. Yun, Y.; Pan, M.; Fang, G.; Gu, Y.; Wen, W.; Xue, R.; Wang, S. An Electrodeposited Molecularly Imprinted Quartz Crystal Microbalance Sensor Sensitized with AuNPs and RGO Material for Highly Selective and Sensitive Detection of Amantadine. RSC Adv. 2018, 8, 6600-6607. [CrossRef]

31. Yu, C.; Simmons, B.A.; Singer, S.W.; Thelen, M.P.; VanderGheynst, J.S. Ionic Liquid-Tolerant Microorganisms and Microbial Communities for Lignocellulose Conversion to Bioproducts. Appl. Microbiol. Biotechnol. 2016, 100, 10237-10249. [CrossRef] [PubMed]

32. Zhao, B.; Al Rasheed, H.; Ali, I.; Hu, S. Efficient Enzymatic Saccharification of Alkaline and Ionic Liquid-Pretreated Bamboo by Highly Active Extremozymes Produced by the Co-Culture of Two Halophilic Fungi. Bioresour. Technol. 2020, $319,124115$. [CrossRef] [PubMed]

33. Jiang, L.; Dai, J.; Sun, Y.; Xiu, Z. The Effects of Ionic Liquid 1-Ethyl-3-Methylimidazolium Trifluoromethanesulfonate on the Production of 1,3-Propanediol from Crude Glycerol by Microbial Consortium. Bioprocess Biosyst. Eng. 2018, 41, 1079-1088. [CrossRef] [PubMed]

34. Zhu, W.; Gao, H.; Li, P.; Li, Y.; Zhang, J.; Bai, H. The Interaction between Microbes and Electrodes Decorated with Bio-Reduced Graphene Oxide - from an Electrochemical Point of View. J. Chem. Technol. Biotechnol. 2020. [CrossRef]

35. Mintz-Hemed, N.; Yoetz-Kopelman, T.; Convertino, A.; Freeman, A.; Shacham-Diamand, Y. Whole-Cell Electrochemical Biosensor Integrating Microbes with Si Nanowire-Forest. J. Electrochem. Soc. 2017, 164, B253-B257. [CrossRef]

36. Trindade, E.K.; Silva, B.V.; Dutra, R.F. A Probeless and Label-Free Electrochemical Immunosensor for Cystatin C Detection Based on Ferrocene Functionalized-Graphene Platform. Biosens. Bioelectron. 2019, 138, 111311. [CrossRef]

37. Sun, C.; Liao, X.; Huang, P.; Shan, G.; Ma, X.; Fu, L.; Zhou, L.; Kong, W. A Self-Assembled Electrochemical Immunosensor for Ultra-Sensitive Detection of Ochratoxin A in Medicinal and Edible Malt. Food Chem. 2020, 315, 126289. [CrossRef]

38. Fu, L.; Zheng, Y.; Zhang, P.; Zhang, H.; Xu, Y.; Zhou, J.; Zhang, H.; Karimi-Maleh, H.; Lai, G.; Zhao, S.; et al. Development of an Electrochemical Biosensor for Phylogenetic Analysis of Amaryllidaceae Based on the Enhanced Electrochemical Fingerprint Recorded from Plant Tissue. Biosens. Bioelectron. 2020, 159, 112212. [CrossRef]

39. Zhang, M.; Pan, B.; Wang, Y.; Du, X.; Fu, L.; Zheng, Y.; Chen, F.; Wu, W.; Zhou, Q.; Ding, S. Recording the Electrochemical Profile of Pueraria Leaves for Polyphyly Analysis. ChemistrySelect 2020, 5, 5035-5040. [CrossRef] 
40. Amor-Gutiérrez, O.; Costa-Rama, E.; Arce-Varas, N.; Martínez-Rodríguez, C.; Novelli, A.; Fernández-Sánchez, M.T.; Costa-García, A. Competitive Electrochemical Immunosensor for the Detection of Unfolded P53 Protein in Blood as Biomarker for Alzheimer's Disease. Anal. Chim. Acta 2020, 1093, 28-34.

41. Karimi-Maleh, H.; Orooji, Y.; Ayati, A.; Qanbari, S.; Tanhaei, B.; Karimi, F.; Alizadeh, M.; Rouhi, J.; Fu, L.; Sillanpää, M. Recent Advances in Removal Techniques of Cr(VI) Toxic Ion from Aqueous Solution: A Comprehensive Review. J. Mol. Liq. 2020, 115062. [CrossRef]

42. Fu, L.; Wu, M.; Zheng, Y.; Zhang, P.; Ye, C.; Zhang, H.; Wang, K.; Su, W.; Chen, F.; Yu, J.; et al. Lycoris Species Identification and Infrageneric Relationship Investigation via Graphene Enhanced Electrochemical Fingerprinting of Pollen. Sens. Actuators B Chem. 2019, 298, 126836. [CrossRef]

43. Shipovskov, S.; Saunders, A.M.; Nielsen, J.S.; Hansen, M.H.; Gothelf, K.V.; Ferapontova, E.E. Electrochemical Sandwich Assay for Attomole Analysis of DNA and RNA from Beer Spoilage Bacteria Lactobacillus Brevis. Biosens. Bioelectron. 2012, 37, 99-106. [CrossRef] [PubMed] 